\title{
The Analysis of the Residual Stress Evolution during Cycling Oxidation of the Ni-base Superalloys at High Temperature
}

\author{
Wojciech J. NOWAK ${ }^{*}$, Kamil OCHAŁ, Ryszard FILIP, Bartek WIERZBA
}

\begin{abstract}
The lifetime of the elements made of Ni-base superalloys can be strongly increased by introducing compressive stresses. Such stresses increase the resistance of cracks nucleation and formation during cyclic loads. Therefore, it is important to know how the stresses in the cold rolled Ni-based superalloys evolve during the service. $\mathrm{Ni}$-base superalloys are dedicated to the usage at elevated temperature. However, exposing the Ni-based superalloys to high temperature results in their oxidation. So far, not a single work on the studies of the residual stress evolution in the Ni-based superalloys during cycling oxidation at high temperature was performed. Thus in the present study the residual stress in the materials in the as-received conditions and the changes in the residual stresses during cycling oxidation of IN 625 and IN 718 at $1273 \mathrm{~K}$ in air was investigated and described. The obtained results showed differences in the residual stresses level measured for investigated alloys. It was also found that thermal cycling of studied alloys influences the residual stresses. However even after the end of the test, the measured residual stresses were still compressive. Slightly different oxidation resistance was found for the studied alloys, namely, IN 718 was found to be more prone to oxide scale spallation. The latter was correlated with different alloy chemical composition, which results in formation of $\delta$ - phase in IN 718. The dissolution of $\delta$ - phase during high temperature exposure resulted in formation of sub-scale enriched with $\mathrm{Nb}$ and $\mathrm{Ti}$ in the near oxide scale/substrate interface. The latter was claimed to have a negative effect on oxide scale adherence.
\end{abstract}

Keywords: cyclic oxidation test; Inconel 625; Inconel 718; microstructure changes; Ni-base superalloys; oxide scale; residual stress

\section{INTRODUCTION}

Nickel-base superalloys, such as Inconel 625 and Inconel 718 possess relatively good corrosion resistance and mechanical properties, especially at high temperature [1-5]. The production of nickel-base superalloy components involves thermal and mechanical processing, which may introduce thermal gradients or strain gradients, which could in turn result in the development of residual stresses. Mechanical processes that introduce residual stresses include traditional thermomechanical manufacturing like forging and cold or hot rolling $[6,7]$ and post processing methods like machining $[8,9]$, grinding $[8,10]$, and shot peening $[11,12]$. Thermally generated residual stresses originate from non-uniform cooling and heating, or thermal treatments with mechanical constraints [8]. It is important to be able to accurately measure and predict residual stresses during manufacturing and post processing of materials in order to combat them, or account for them in design [13]. The residual stresses are produced as a consequence of inhomogeneous plastic deformation and severe heat generation. Compressive stresses are generally beneficial when taking fatigue into account, whereas tensile residual stresses are usually considered to be detrimental since they can accelerate the formation and propagation of fatigue cracks [14].

Inconel 718 is mostly used in gas turbine industries [15-17], compressor and turbine disks, blades, tubes, shafts, and fasteners due to its ability to be used in wrought or cast forms, high strength, weldability and fabricability $[18,19]$. Inconel 625 has been well known and widely used in different industries such as: chemistry, aerospace, nuclear power and others, thanks to its superior thermal, creep properties and fatigue $[20,21]$.

These superalloys do not own adequate oxidation resistance in their service environment, especially in damaged areas where the bare metal is exposed to the oxygen containing atmosphere [22]. The high oxidation rate is the main reason for the failure of hot section turbine blades [23]. When the clean sample is exposed to an oxygen rich gas, small impinging nuclei of all the thermodynamically stable oxides develop on the surface and coalesce rapidly to form a continuous layer. During the transient stage, when the observed oxidation rate is rapid, all the elements in the alloy oxidize and the amounts of various oxides in the layer are approximately proportional to the concentration of the elements in the alloy [24, 25]. After the transient stage, usually protective oxide scale is formed. Then, the high temperature oxidation can involve the formation of external oxide scales, oxidation of reactive elements and also internal oxidation [26].

The following experimental work was performed in order to measure the residual stress changes during cyclic oxidation of Inconel 718 and Inconel 625 at elevated temperature. The influence of microstructure evolution on stress distribution in the near-surface region of studied alloys will be discussed as well.

\section{MATERIALS AND METHODS}

Two representatives from the Inconel family, namely Inconel 625 and Inconel 718 with the nominal composition given in Tab. 1, were investigated in terms of changes in the residual stress during cycling oxidation at high temperature.

Prior the cyclic oxidation the samples were cut from the cooled rolled sheets into pieces with dimensions $20 \times$ $20 \times 1 \mathrm{~mm}$. Then the samples were ground using sand paper with an increasing gradation up to 1000 grit. After grinding, all of the samples were cleaned in ultrasonic bath in ethanol and dried by compressed air. After cleaning the samples were analyzed in term of residual stresses and then subjected to cyclic oxidation test. The thermal shock test was carried out in furnace XERION XTUBE made by Xerion Advance Heating Ofentechchnik GmbH (Freiberg, Germany). Prior to exposure the weight of all of five specimens per each alloy was measured. All five specimens from each studied alloy were put into the furnace with a tube of $300 \mathrm{~mm}$ diameter and subsequently subjected to cyclic oxidation test. Each cycle consists of 
2.5 hours of heating at $1273 \mathrm{~K}$ and 0.5 hours cooling in glass tube by fan. Cycling oxidation test was performed up to 298 cycles (745 hot hours). After 2, 10, 33, 98, 298 cycles the samples were taken out of the furnace and weighted using microbalance RADWAG WAA 100/C/1 with $0.1 \mathrm{mg}$ accuracy to determine the oxidation kinetics. The residual stress measurement was performed with PROTO iXRD COMBO produced by Proto Manufacturing Ltd (Ontario, Canada) on samples before and after the cyclic oxidation test. For residual stress measurement the Mn-cathode was used. This in combination with Ni-base matrix of measured material allows for residual stress measurement on effective depth up to $5 \mu \mathrm{m}$ [27]. Residual stresses were calculated using $\sin 2 \Psi$ method. Parameters of radiation source were as follows: filament voltage 20 $\mathrm{kV}$, current $4 \mathrm{~mA}$. The stress was measured in two perpendicular directions: $X$ and $Y$. The result obtained for "single" measurement is an average of eight measurements and it is given as an average residual stress $(\mathrm{MPa})$ with standard deviation. After the iXRD measurement, the chemical composition of the oxidized samples surface was analysed using a glow discharge optical emission spectrometer (GD-OES) made by Horiba Jobin Yvon (Longjumeau, France). The GD-OES depth profiles were quantified using the procedure described in references [2830]. The cross-sections of the samples after exposure were prepared in the following way: the samples surfaces were sputtered with a thin gold layer to provide electrical conductivity. Then the samples were electroplated with nickel and mounted using epoxy resin. The cross sections were ground and polished on the fine polishing with 0.25 $\mu \mathrm{m}$ silica suspension. The cross-sections were observed by a light optical microscope (LOM) Nikon EPIPHOT 300 (Nikon, Tokyo, Japan) and analyzed by scanning electron microscope (SEM), Hitachi S3400N (Hitahi, Tokyo, Japan), equipped with an energy dispersive spectroscopy (EDS) detector.

Table 1 The nominal composition of Inconel 625 and Inconel 718

\begin{tabular}{|c|c|c|c|c|c|c|c|c|c|c|c|c|}
\hline \multirow{2}{*}{ Alloy } & \multicolumn{12}{|c|}{ Elements Content (wt. \%) } \\
\hline & $\mathrm{Ni}$ & $\mathrm{Cr}$ & $\mathrm{Ta}$ & $\mathrm{Co}$ & Mo & $\mathrm{Nb}$ & $\mathrm{Al}$ & $\mathrm{Ti}$ & $\mathrm{Fe}$ & $\mathrm{Mn}$ & $\mathrm{Si}$ & $\mathrm{C}$ \\
\hline IN 625 & Bal. & 21.5 & $3.6^{*}$ & 0.5 & 9.0 & $3.6^{*}$ & 0.4 & 0.4 & 5.0 & 0.5 & 0.5 & 0.1 \\
\hline IN 718 & BASE & 20.0 & $5.0^{*}$ & 1.0 & 3.1 & $5.0^{*}$ & 0.6 & 0.9 & 18.1 & 0.3 & 0.3 & 0.08 \\
\hline
\end{tabular}

* total amount of $\mathrm{Ta}$ and $\mathrm{Nb}$.

\section{RESULTS \\ 3.1 Mass Change}

The mass changes of IN 625 and IN 718 during cycling oxidation up to 300 cycles are shown in Fig. 1. It can be clearly seen that during the early stage of exposure, for both studied alloys a mass gain is observed up to 30 cycles. After the mentioned 30 cycles the alloys started to behave differently, namely, for IN 625 a continuous increase of specific mass gain was observed, while for IN 718 a mass loss is obtained. At the end of the test (298 cycles) a positive mass change is observed for IN 625 and its value at the end of the test was $2.5 \mathrm{mg} \cdot \mathrm{cm}^{-2}$. Contrary, for IN 718 a negative mass change is visible and at the end of the test its value was equal to almost $-7 \mathrm{mg} \cdot \mathrm{cm}^{-2}$.

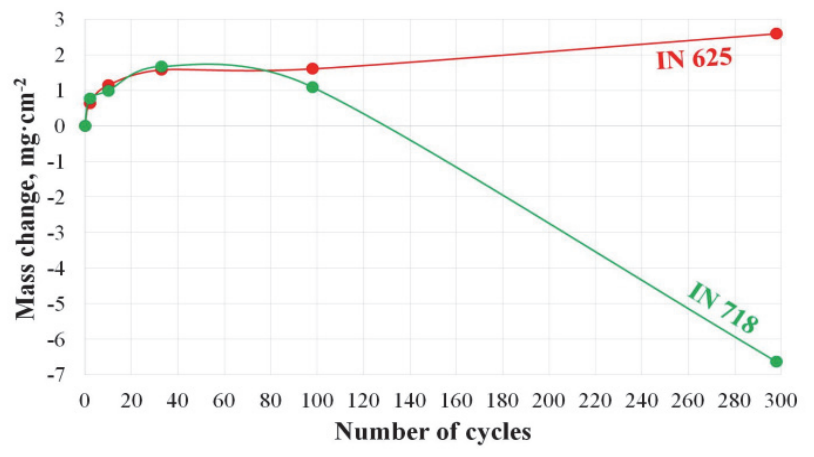

Figure 1 Mass changes obtained during cyclic oxidation of IN 615 and IN 718 at $1273 \mathrm{~K}$ in air

\subsection{Residual Stress Analysis}

Residual stress measurement prior and after exposure up to 298 cycles is shown in Fig. 2. The enlarged part of the plot (up to 100 cycles) is presented in Fig. 2b. It is shown that the level of residual stress in both alloys differs.
For the IN 718 more negative stresses were measured prior and after exposure as compared to IN 625. The measured stresses in the as-received conditions were around -190 $\mathrm{MPa}$ and $-350 \mathrm{MPa}$ for IN 625 and IN 718 respectively. During cyclic exposure the residual stress level changes dynamically in both measured directions for each alloy. An increase in residual stress is observed (less negative value) after 2 cycles and its values are -30 and $-300 \mathrm{MPa}$ for IN 625 and IN 718 respectively (Fig. 2).
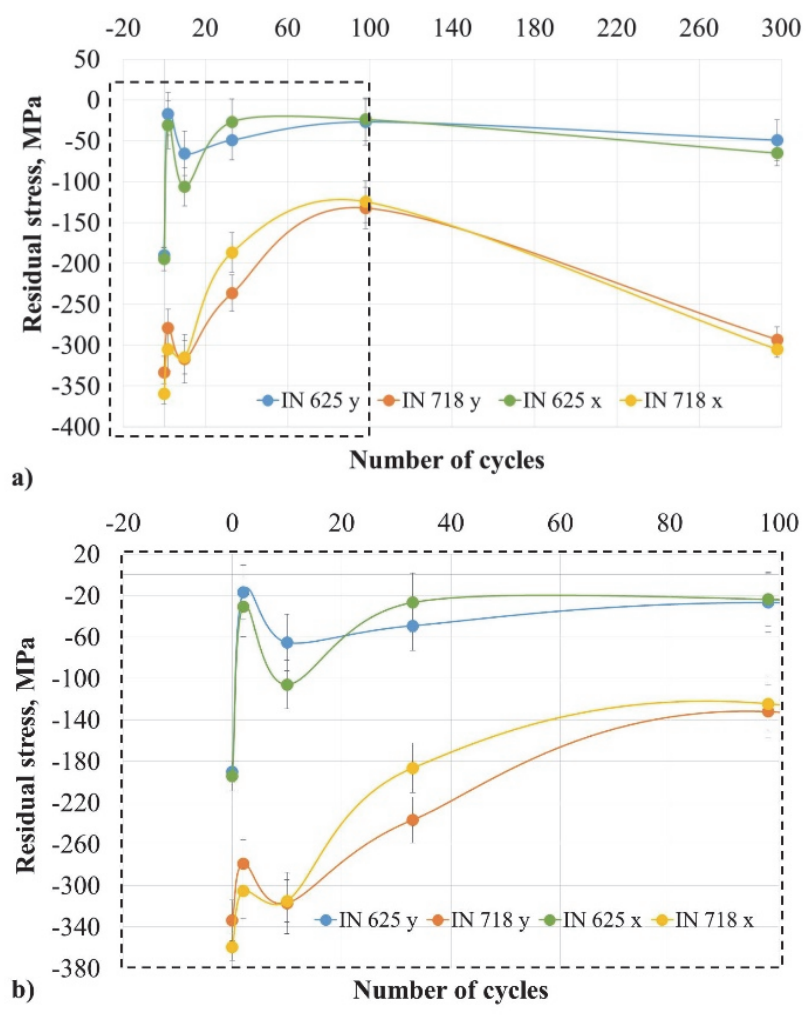

Figure 2 Residual stresses measured by iXRD on studied alloys: a) up to 298 cycles and b) enlarged fragment up to 98 cycles. 
After 10 cycles another decrease in value of residual stresses is found up to $-80 \mathrm{MPa}$ for IN 625 . In case of IN 718 a residual stress at the same level, i.e. $-300 \mathrm{MPa}$ was measured. Further cycling resulting in an increase of residual stress is observed up to $-30 \mathrm{MPa}$ (IN 625) and $-200 \mathrm{MPa}(\mathrm{IN} 718)$ after 33 cycles and $-25 \mathrm{MPa}(\mathrm{IN} 625)$ and $-130 \mathrm{MPa}$ (IN 718). At the end of the test (298 cycles) another drop of the measured residual stress is observed. It should be mentioned, that the drop of residual stresses obtained for IN 718 is more rapid $(-300 \mathrm{MPa}$ measured at the end of the test) in comparison with IN 625 (-60 MPa measured at the end of the test). Moreover, it can be observed, that even after the end of the test, the values of measured residual stresses are higher (less negative) than measured prior oxidation. This observation is valid for both studied alloys.
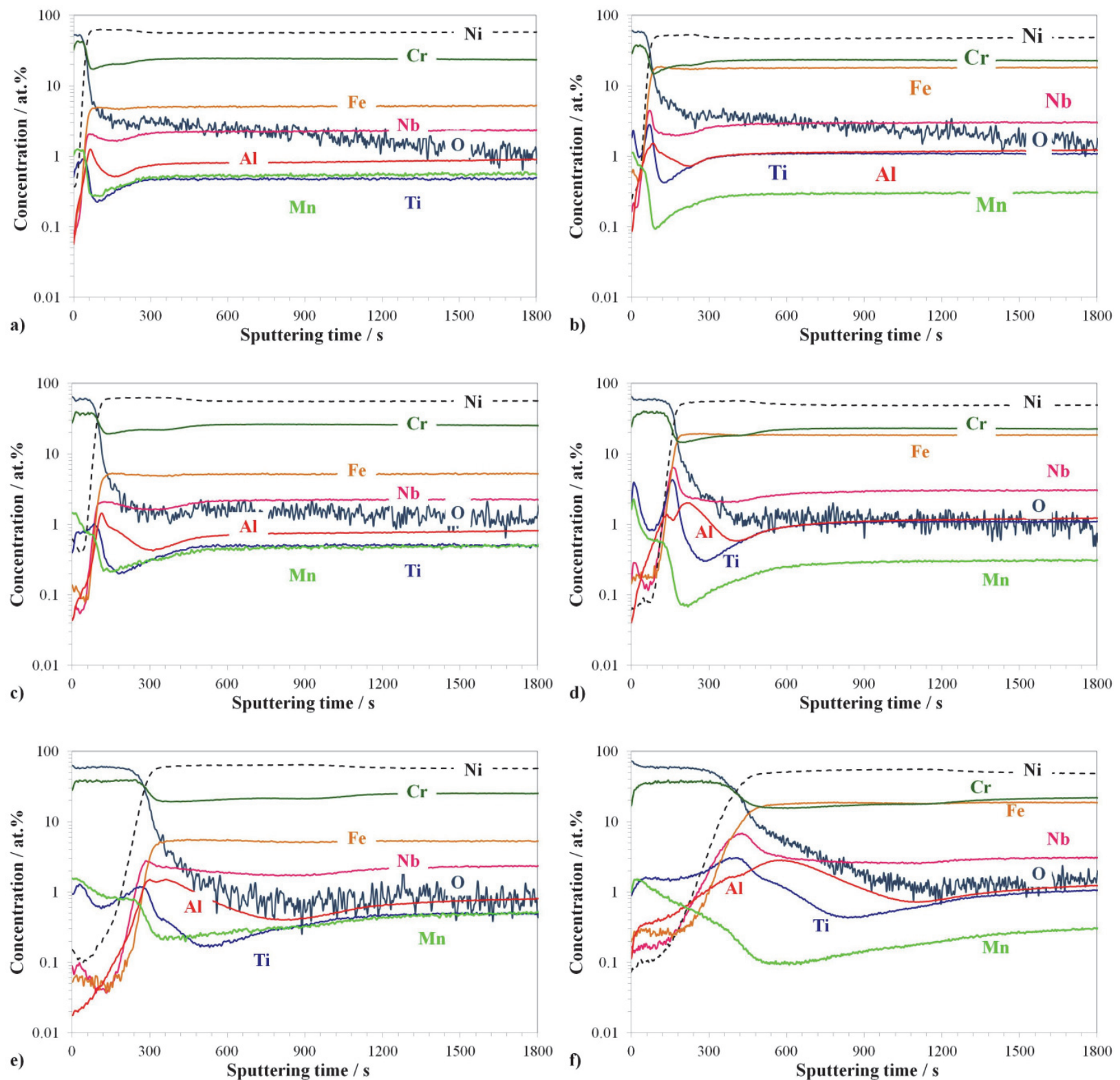

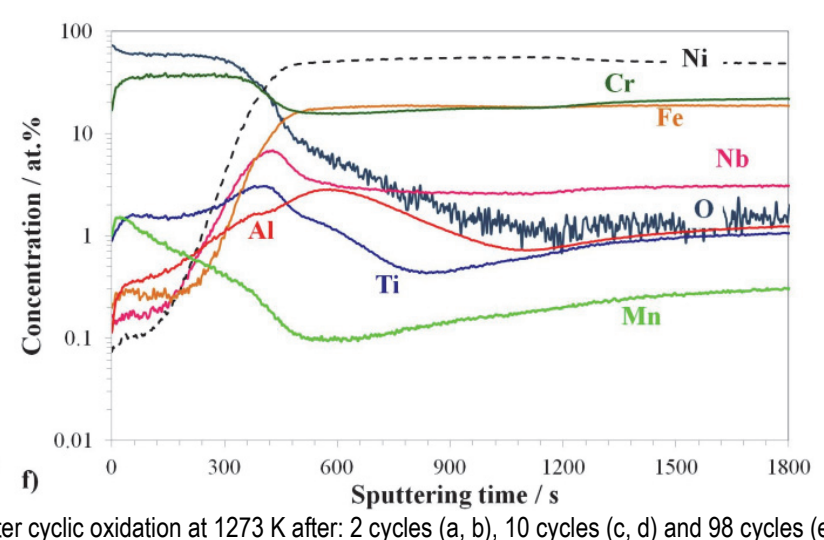

\subsection{Oxidation Products Characteristic 3.3.1 GD-OES Depth Profiling}

On the basis of mass change plot (Fig. 1) the samples exposed for 2, 10 and 98 cycles from both alloys were selected for GD-OES depth profiling. The obtained GDOES depth profiles are shown in Fig. 3. The GD-OES depth profile measured on IN 625 after 2 cycles is shown in Fig. 3a. It reveals the enrichment in $\mathrm{Cr}$ and $\mathrm{O}$ profile up to $75 \mathrm{~s}$. After $75 \mathrm{~s}$ an increase of $\mathrm{Al}$ and decrease in $\mathrm{O}$ concentration is observed. Similar observation can be noticed on depth profiles on IN 625 after 10 cycles (Fig. 3c) and 98 cycles (Fig. 3e). The difference is in increasing time for measurement of $\mathrm{Cr}$ and $\mathrm{O}$ co-enrichment $(100 \mathrm{~s}$ and $300 \mathrm{~s}$ for 10 and 98 cycles respectively) as well as for measurement of Al-enrichment.

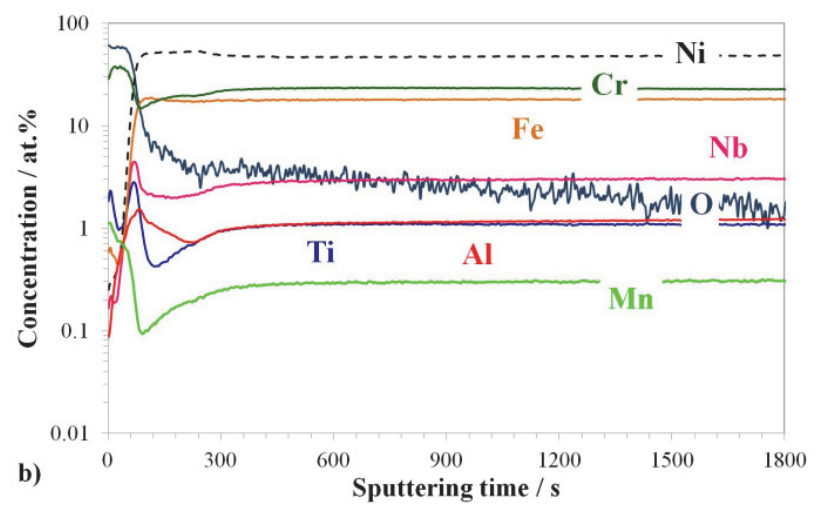

for IN 625, a co-enrichment of $\mathrm{Nb}$ and $\mathrm{Ti}$ just after enrichment of $\mathrm{Cr}$ and $\mathrm{O}$ after all the exposure times is observed (Fig. 3b, d and e). The important finding by GDOES depth profiling is that either no or negligible Ta

Figure 3 GD-OES depth profiles performed on IN 625 (a, c, e) and IN 718 (b, d, f) after cyclic oxidation at $1273 \mathrm{~K}$ after: 2 cycles (a, b), 10 cycles (c, d) and 98 cycles (e, f).

A similar oxide scale chemistry is measured for IN 718 after 2 (Fig. 3b), 10 (Fig. 3d) and 98 (Fig. 3f) cycles. However, it should be noticed, that the increase in time of $\mathrm{Cr}$ and $\mathrm{O}$ co-enrichment measurement is bigger for IN 718 than for IN 625. Moreover, different from depth profiles 
content in both studied alloys was detected, therefore the profile of Ta was not shown in the GD-OES depth profiles.

\subsubsection{Microstructure Analysis}

A typical microstructure of the oxide scale formed on IN 625 during high temperature oxidation is shown in Fig. 4. On top of the image a Ni-coating is present. Below Niplating, an external oxide scale is visible. To unify, external oxide scale will be designed as EOS. Below EOS, and internal oxidation zone (IOZ) is present. In this zone aluminium oxide precipitates are found in the studied alloys. Below IOZ a base alloy (substrate) is present. Such oxide scale microstructure, or at least a similar one, is observed for both studied alloys after exposure for different times (as shown in Fig. 5a to Fig. 5f). For both investigated alloys a thickening of EOS accompanied with increasing depth of IOZ is observed as shown in Fig. 5a to Fig. 5f.

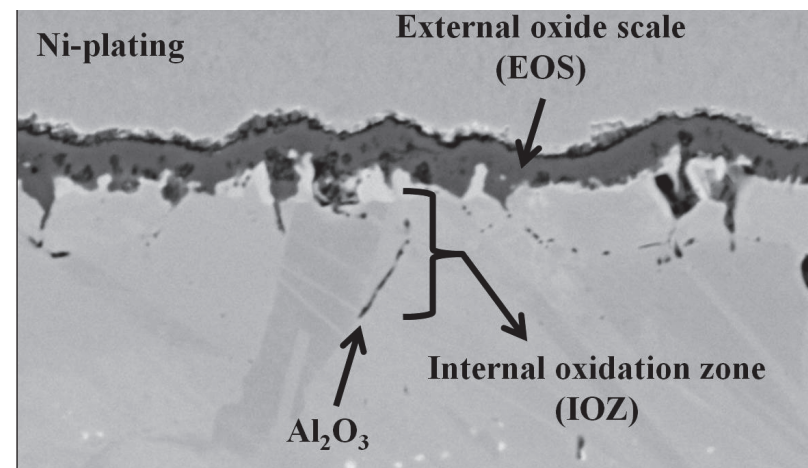

Substrate

$10 \mu \mathrm{m}$

Figure 4 SEM/BSE image showing typical microstructure obtained on IN 625 after air exposure at $1273 \mathrm{~K}$ up to 25 hours.

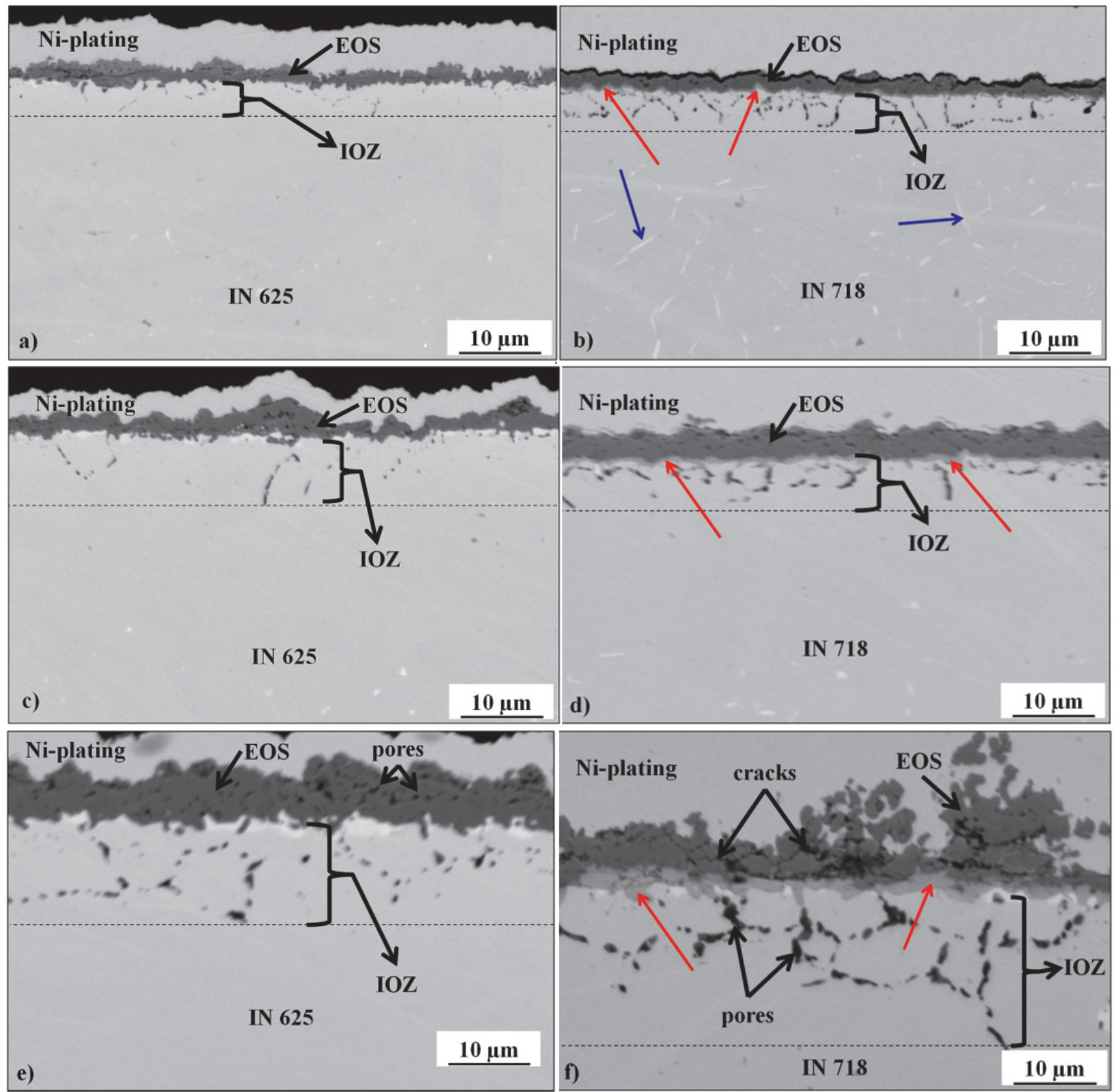

Figure 5 SEM/BSE images performed on the cross-sections of IN $625(a, c, e)$ and IN $718(b, d, f)$ after cyclic oxidation at $1273 \mathrm{~K}$ after: 2 cycles (a, b), 10 cycles (c, d) and 98 cycles $(e, f)$. 

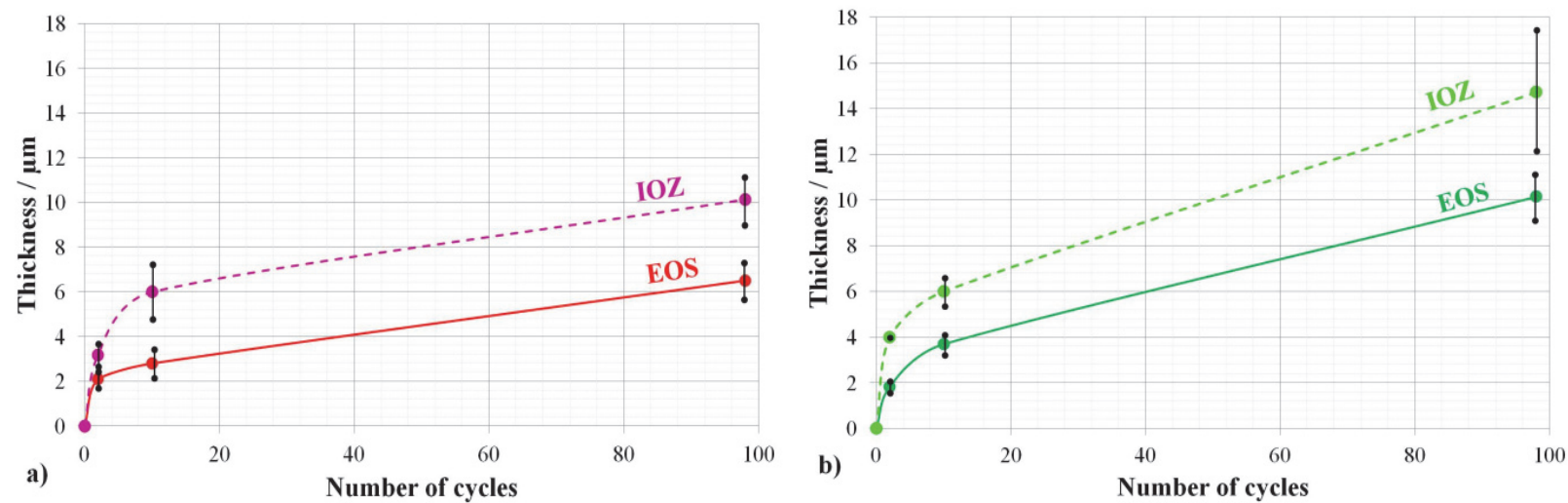

Figure 6 Plots showing an average thickness of external oxide scale (EOS) and internal oxidation zone (IOZ) measured on cross-sections of: a) IN 625 and b) IN 718 after exposure.

Based on images of the cross-sections of studied alloys after exposure, thicknesses of the EOS and IOZ were performed. The obtained results for IN 625 and IN 718 are shown in Fig. 5a and Fig. 5b respectively. For both alloys a thickening of EOS and IOZ is observed with increasing exposure time. However, it is worth noticing that the slope of the curves obtained for IN 718 is slightly higher as compared with that obtained for IN 625. After 100 cycles the thickness of EOS obtained for IN 625 is $6.5 \pm 1.1 \mu \mathrm{m}$ and IOZ $10.1 \pm 1.5 \mu \mathrm{m}$, while for IN 718 EOS was 10.1 $\pm 1.5 \mu \mathrm{m}$ and IOZ was $14.7 \pm 3.8 \mu \mathrm{m}$ in thickness. Moreover, for IN 718 the formation of an additional oxide sub-scale at the EOS/substrate was observed, as marked by the red arrow in Fig. 5b, Fig. 5d, Fig. 5e. Also a presence of an additional phase marked by the blue arrows in Fig. 5b was observed. For IN 718, the increasing exposure time results not only in thickening of the EOS, IOZ, and also in the thickening of the light grey subscale (marked by the red arrows in Fig. 5b, Fig. 5d, Fig. $5 f$ and Fig. 6b), but also in an increase of the depth of precipitation free zone (precipitates marked by blue arrows in Fig. 7a, Fig. 7b, Fig. $7 \mathrm{c})$. The precipitation free zone depth increases with increasing number of cycles and after 98 cycles PFZ depth is equal to $68 \pm 6 \mu \mathrm{m}$ (Fig. 8). Moreover, a large number of cracks and non-uniformity in the EOS thickness, which at some locations is embedded into Ni-plating, is observed for IN 718 after exposure up to 98 cycles.

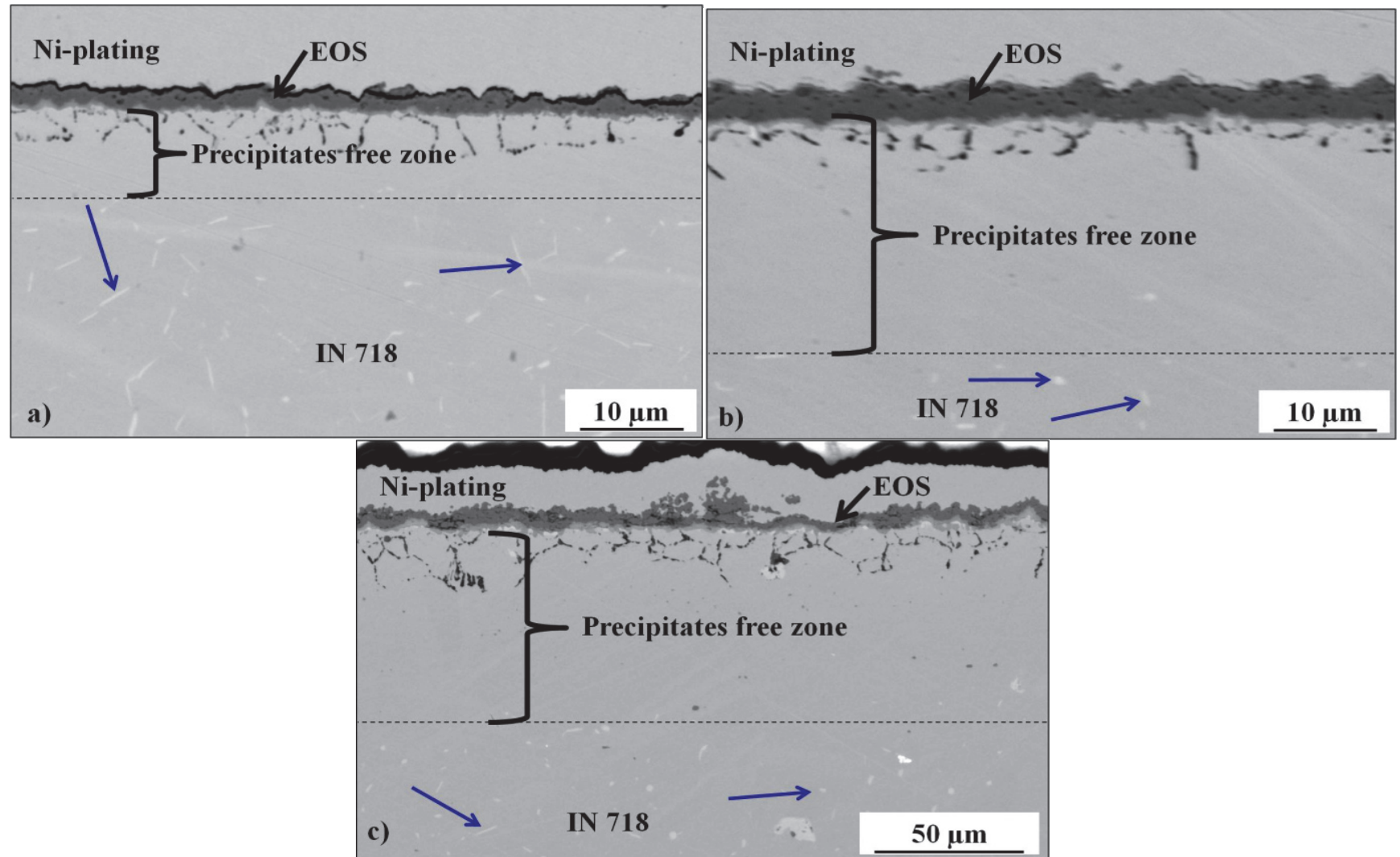

Figure 7 SEM/BSE images performed on the cross-sections of IN 718 after cyclic oxidation at $1273 \mathrm{~K}$ after: 2 cycles (a), 10 cycles (b) and 98 (c) cycles showing precipitation free zone (PFZ). 


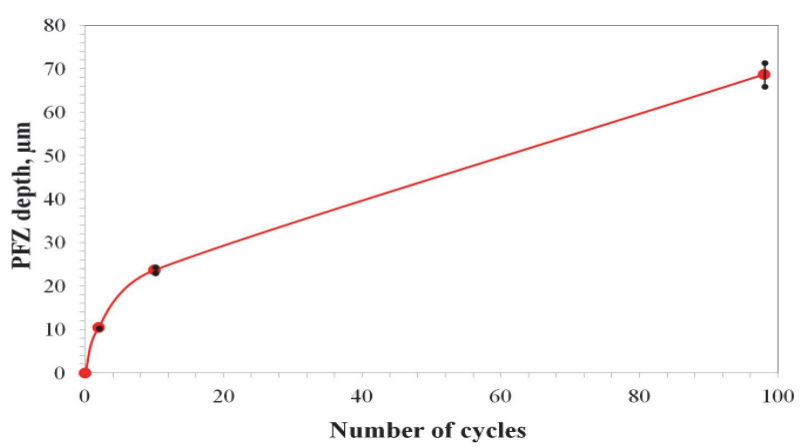

Figure 8 Plot showing the increase on precipitation free zone (PFZ) as a function of exposure cycles for obtained for IN 718.

\section{DISCUSSION}

The residual stress measurement results performed on studied alloys in the as-received condition revealed negative values of stresses, which, according to the iXRD nomenclature, indicates the presence of compressive stresses [31]. The residual stresses change during exposure to high temperature. After 2 cycles of exposure stresses become less compressive for both alloys. The mass change measurement showed mass gain at a similar level at this stage for both studied alloys. Moreover, the cross-sectional investigation revealed that both alloys formed external oxide scales with thickness around $2 \mu \mathrm{m}$. Considering the fact that the effective depth for iXRD measurement for studied alloys is $5 \mu \mathrm{m}$, it can be concluded that despite the stresses in the EOS, also roughly $3 \mu \mathrm{m}$ of substrate is taken into account during residual stress measurement at the present stage. The melting temperatures of the studied alloys are in the range $1563-1623 \mathrm{~K}$ for IN 625 and 1533 - $1609 \mathrm{~K}$ for IN 718 [32]. It is known, that the recrystallization temperature $\left(T_{\mathrm{R}}\right)$ usually occurs at $T_{\mathrm{R}}=$ $0.4 T_{\mathrm{m}}\left(T_{\mathrm{m}}\right.$ - melting temperature) [33], then for the studied alloys $T_{\mathrm{R}}$ occurs at temperature range $625-649 \mathrm{~K}$ and 613 $-643 \mathrm{~K}$ for IN 625 and IN 718 respectively. Since the exposure temperature in the present study was $1273 \mathrm{~K}$, the recrystallization in the material surely occurred. Then, the recrystallization of the substrate, at least in the near-surface region, is one of the factors decreasing the residual compressive stresses after 2 cycles of exposure. After 10 cycles increased residual compressive stresses for both studied alloys were measured. This increase is most probably due to the increase of EOS and IOZ thickness for both studied alloys. Measured thickness of EOS for IN 625 after 10 cycles was about $3 \mu \mathrm{m}$ while for IN 718 it was about $4 \mu \mathrm{m}$, then the stresses in the substrate still participated in the overall measured residual stresses. However, an increase in the IOZ was also measured. The reaction between $\mathrm{Al}$ and $\mathrm{O}$ caused the oxygen intake leading to the formation of internal oxides $\mathrm{Al}_{2} \mathrm{O}_{3}$. This in turn caused the volume expansion which lead to further compression of the matrix entrapped in between the internal oxide precipitates. The latter caused an increase of compressive stresses, and then more negative values of residual stresses were measured. Between 10 and 98 cycles a decrease in the measured residual stresses (less negative values) was obtained. After 98 cycles, the measured thicknesses of EOS were 6.5 and $10 \mu \mathrm{m}$, which means that the residual stresses were measured in the external oxide scale (EOS). The decrease in the compressive stresses can be explained by the EOS microstructure. Namely, for IN 625 formation of the pores within the EOS is observed. These pores can act in the stress relaxation process. Slightly different situation is observed for IN 718 after 98 cycles of exposure. The drop in the compressive stresses is also observed; however, in the microstructure of EOS a number of cracks is present within EOS. This means that the stress level in combination with the EOS thickness was so high that the system relaxed the stresses by the cracks formation. This in turn caused spallation of part of the external oxide scale. The latter is confirmed by drop in the mass change curve for IN 718 after 98 cycles. After 298 cycles, another increase in compressive stresses measured for both alloys is noticed. In case of IN 625, the most probable reason for this is that the thickness of EOS is near the critical oxide scale thickness and leads to the accumulation of the stresses shortly before relaxation by cracks formation. For IN 718 the increased compressive stresses are most likely caused by further spallation of the external oxide scale, which caused thinning of EOS and enabling of measurement of the stresses in the IOZ of IN 718 after 298 cycles. The increased compressive stresses (more negative values) are caused by the extensive formation of internally oxidized $\mathrm{Al}_{2} \mathrm{O}_{3}$ precipitates, its increased volume and compression of the substrate in IOZ.

Different level of measured stresses at prior exposure stage can be correlated with slightly different chemical composition, namely, IN 718 contains much more Fe, and slightly more $\mathrm{Nb}$ and $\mathrm{Ti}$. As observed, during exposure at high temperature of IN 718, formation of additional phases in the substrate, which were not present in the material in the as-received condition, was found. The SEM/EDS measurement revealed that these phases are enriched with $\mathrm{Nb}$ and $\mathrm{Ti}$. Based on the literature data, such phases were identified as $\delta$ - phases [34] with orthorhombic DOa structure with Ni3Nb stoichiometry. Based on SEM/EDS analysis and GD-OES depth profiles, formation of an additional sub-layer enriched with $\mathrm{Nb}$ and $\mathrm{Ti}$ below the outer $\mathrm{Cr}_{2} \mathrm{O}_{3}$ at the EOS/IOZ after exposure was found. Thickening of this sub-scale was observed as well. The latter was accompanied with widening of the precipitation free zone (PFZ) below the IOZ. This indicates that during exposure the $\mathrm{Nb} / \mathrm{Ti}$ rich $\delta$ - phases became dissolved and $\mathrm{Nb}$ and $\mathrm{Ti}$ diffused out to form $\mathrm{Cr} / \mathrm{Nb} / \mathrm{Ti}$-mixed oxide at EOS/IOZ interface in case of IN 718. After longer exposure time (starting from 98 cycles) a spallation of the oxide scale if found for IN 718. This in combination with previous observation suggests that the formation of oxide containing $\mathrm{Nb}$ and $\mathrm{Ti}$ weakens the EOS adherence to the substrate

\section{CONCLUSIONS}

In the present work the residual stresses changes during cycling thermal exposure at $1273 \mathrm{~K}$ in air of two representatives from Inconel family, namely IN 625 and IN 718 in the form of cooled rolled foils were studied. Based on obtained results, the following conclusions can be made:

Cold rolling introduces compressive stresses into the material. However, as shown in the present work, the chemical composition of the alloys results in big differences in the level of residual stresses, 
- Thermal cycling of studied Ni-base superalloys influences the residual stress in the material; however the changes are not monotonic,

- The residual stresses measured by iXRD method are an average of the stresses in formed oxide scale as well as in the base alloy,

- Recrystallization of the base material was proposed as one of the factors responsible for stress relaxation (decrease of residual stress) noticed at early stage of oxidation,

Further decrease in measured compressive stresses was connected with formation of pores (IN 625) and/or cracks nucleation and propagation (IN 718) in the oxide scale,

- An extensive oxide scale spallation was observed for IN 718 and was associated with formation of $\mathrm{Cr} / \mathrm{Nb} / \mathrm{Ti}$ mixed sub-scale near the EOS/IOZ interface. Intensive scale spallation allowed measurement of the stresses in the IOZ of IN 718 after 298 cycles. The measurement revealed increase in compressive stresses, which was correlated with formation of internally oxidized $\mathrm{Al}_{2} \mathrm{O}_{3}$ precipitates, which caused compression of embedded substrate matrix.

\section{Acknowledgements}

The research was conducted within the scope of the TECHMASTRATEG project (number 406725) financed by The National Centre for Research and Development (Narodowe Centrum Badań i Rozwoju).

\section{REFERENCES}

[1] Li, D., Guo, Q., Guo, S., Peng, H., \& Wu, Z. (2011). The microstructure evolution and nucleation mechanisms of dynamic recrystallization in hot-deformed Inconel 625 superalloy. Materials and Design, 32, 696-705. https://doi.org/10.1016/j.matdes.2010.07.040

[2] Thomas, A., El-Wahabi, M., Cabrera, J. M., \& Prado, J. M. (2006). High temperature deformation of Inconel 718 . Journal of Materials Processing Technology, 177, 469-472. https://doi.org/10.1016/j.jmatprotec.2006.04.072

[3] Kuo, C. M., Yang, Y. T., Bor, H. Y., Wei, C. N., \& Tai, C. C. (2009). Aging effects on the microstructure and creep behavior of Inconel 718 superalloy. Materials Science and Engineering, A510-511, 289-294. https://doi.org/10.1016/j.msea.2008.04.097

[4] Aba-Perea, P. E., Pirling, T., Withers, P. J., Kelleher, J., Kabra, S., \& Preuss, M. (2016). Determination of the high temperature elastic properties and diffraction elastic constants of Ni base superalloys. Materials and Design, 89 , 856-863. https://doi.org/10.1016/j.matdes.2015.09.152

[5] Nowak, W. J. (2018). Effect of Surface Roughness on Early Stage Oxidation Behavior of Ni-Base Superalloy IN 625. Applied System Innovation, 1(3), 32. https://doi.org/10.3390/asi1030032

[6] Dye, D., Roder, B. A., Tin, S., Rist, M. A., James, J. A., \& Daymond, M. R. (2014). Modeling and Measurement of Residual Stresses in a Forged IN718 Superalloy Disc. TMS, Warrendale, $P A, 315-322$.

[7] Korsunsky, A. M., Regino, G. M., Latham, D. P., Li, H. Y., \& Walsh, M .J. (2007). Residual stresses in rolled and machined nickel alloy plates: synchrotron X-ray diffraction measurement and three-dimensional eigen strain analysis. The Journal of Strain Analysis for Engineering Design, 42, 1-12. https://doi.org/10.1243/03093247JSA260
[8] Kandil, F. A., Lord, J. D., Fry, A. T., \& Grant, P. V. (2001). A Review of Residual Stress Measurement Methods-A Guide to Technique Selection, NPL Report, MATC.4, 1-42.

[9] Ulutan, D., Alaca, B. E., \& Lazoglu, I. (2007). Analytical modelling of residual stresses in machining. Journal of Materials Processing Technology, 183, 77-87. https://doi.org/10.1016/j.jmatprotec.2006.09.032

[10] Withers, P. J. \& Bhadeshia, H. K. D. H. (2001). Residual stress Part 2 - nature and origins. Materials Science and Technology, 17, 366-375. https://doi.org/10.1179/026708301101510087

[11] Wang, S., Li, Y., Yao, M., \& Wang, R. (1998). Compressive residual stress introduced by shot peening. Journal of Materials Processing Technology, 73, 64-73. https://doi.org/10.1016/S0924-0136(97)00213-6

[12] Cai, D., Nie, P., Shan, J., Liu, W., Yao, M., \& Gao, Y., (2006). Precipitation and residual stress relaxation kinetics in shot-peened Inconel 718. Journal of Materials Engineering and Performance, 15, 614-617. https://doi.org/10.1361/105994906X124613

[13] Wang, Z., Stoica, A. D., Mab, D., \& Beese, A. M. (2016). Diffraction and single-crystal elastic constants of Inconel 625 at room and elevated temperatures determined by neutron diffraction. Materials Science \& Engineering A, 674, 406-412. https://doi.org/10.1016/j.msea.2016.08.010

[14] El-Khabeery, M. \& Fattouh, M. (1989). Residual stress distribution caused by milling. International Journal of Machine Tools and Manufacture, 29, 391-401. https://doi.org/10.1016/0890-6955(89)90008-4

[15] Choudhury, I. A. \& El-Baradie, M. A. (1998). Machinability of nickel-base super alloys: a general review. Journal of Materials Processing Technology, 77, 278-284. https://doi.org/10.1016/S0924-0136(97)00429-9

[16] Dudzinski, D., Devillez, A., Moufki, A., Larrouquere, D., Zerrouki, V., \& Vigneau, J. (2004). A review of developments towards dry and high speed machining of Inconel 718 alloy, International Journal of Machine Tools and Manufacture, 44, 439-456. https://doi.org/10.1016/S0890-6955(03)00159-7

[17] Chen, Z., Peng, L. R., Avdovic, P., Moverare, J., Karlsson, F., Zhou, J. M., \& Johansson, S., (2014). Analysis of thermal effect on residual stresses of broached Inconel 718 . Advanced Materials Research, 996, 574-579. https://doi.org/10.4028/www.scientific.net/AMR.996.574

[18] Paulonis, D. F. \& Schirra, J. J. (2001). Alloy 718 at Pratt \& Whitney - historical perspective and future challenges, in: E.A. Loria (Ed.), Proc. Int. Symp. Superalloys Var. Deriv, TMS (The Minerals. Metals \& Materials Society), Pittsburgh, PA, 13-23. https://doi.org/10.7449/2001/Superalloys_2001_13_23

[19] Telanga, A., Gillb, A. S., Mannavaa, S. R., Qianc, D., \& Vasudevana, V. K. (2018). Effect of temperature on microstructure and residual stresses induced by surface treatments in Inconel 718 SPF. Surface \& Coatings Technology, 344, 93-101. https://doi.org/10.1016/j.surfcoat.2018.02.094

[20] Pollock, T. M. \& Tim, S. (2006). Nickel-Based Superalloys for Advanced Turbine Engines: Chemistry, Microstructure and Properties. Journal of Propulsion and Power, 22, 361374. https://doi.org/10.2514/1.18239

[21] Wu, L. H. \& Jiang, C. H. (2017). Effect of Shot Peening on Residual Stress and Microstructure in the Deformed Layer of Inconel 625. Materials Transactions, 58(2), 164-166. https://doi.org/10.2320/matertrans.M2016298

[22] Saber, D., Emam, I. S., \& Abdel-Karim, R. (2017). High temperature cyclic oxidation of $\mathrm{Ni}$ based superalloys at different temperatures in air. Journal of Alloys and Compounds, 719, 133-141. https://doi.org/10.1016/j.jallcom.2017.05.130 
[23] Stankowski, A. (2002). Advanced thermochemical cleaning procedures for structural braze repair techniques. Proceedings of ASME Turbo Expo: Power for Land, Sea, and Air, Amsterdam, The Netherlands, 1181-1195. https://doi.org/10.1115/GT2002-30535

[24] Pint, B. A., DiStefano, J. R., \& Wright, I. G. (2006) Oxidation resistance: one barrier to moving beyond Ni-base superalloys. Materials Science \& Engineering A, 415(1), 255-263. https://doi.org/10.1016/j.msea.2005.09.091

[25] Stott, F. H. (1998). The role of oxidation in the wear of alloys. Tribology International, 31(1), 61-71. https://doi.org/10.1016/S0301-679X(98)00008-5

[26] El-Awadi, G. A., Abdel-Samad, S., \& Elshazly, E. S. (2016), Hot corrosion behavior of Ni based Inconel 617 and Inconel 738 superalloys. Applied Surface Science, 378, 224-230. https://doi.org/10.1016/j.apsusc.2016.03.181

[27] Skrzypek, S. J. (2012). New Approach to measuring Residual Macro-Stresses with the application of the Grazing Angle X-Ray Diffraction Geometry, AGH Uczelniane Wydawnictwa Naukowo-Dydaktyczne, Cracow, Poland.

[28] Pfeifer, J. P., Holzbrecher, H., Quadakkers, W. J., \& Speier, J. (1993). Quantitative analysis of oxide films on ODS-alloys using MCs+-SIMS and e-beam SNMS. Fresenius' Journal of Analytical Chemistry, 346, 186-191. https://doi.org/10.1007/BF00321410

[29] Quadakkers, W. J., Elschner, A., Speier, W., \& Nickel, H. (1991). Composition and growth mechanisms of alumina scales on FeCrAl-based alloys determined by SNMS. Applied Surface Science, 52, 271-287. https://doi.org/10.1016/0169-4332(91)90069-V

[30] Nowak, W. J. (2017). Characterization of oxidized Ni-based superalloys by GD-OES. Journal of Analytical Atomic Spectrometry, 32, 1730-1738. https://doi.org/10.1039/C7JA00069C

[31] Brown, D. W., Okuniewski, M. A., Almer, J. D., Balogh, L., Clausen, B., Okasinski, J. S., \& Rabin, B. H. (2013). High energy X-ray diffraction measurement of residual stresses in a monolithic aluminum clad uranium- $10 \mathrm{wt} \%$ molybdenum fuel plate assembly. Journal of Nuclear Materials, 441, 252 261. https://doi.org/10.1016/j.jnucmat.2013.05.064

[32] ASM Specialty Handbook, Nickel, Cobalt, and Their Alloys, Edited by J. R. Davis, Davis \& Associates, ASM International, Materials Park, OH 44073, December 2000, ISBN: 0-87170-685-7

[33] Black, J. T. \& Kohser, R. A. (2012). DeGarmo's Materials and Processes in Manufacturing, ELEVENTH EDITION, Wiley, John Wiley \& Sons, Inc., ISBN-13 978-0-470-924679

[34] Mahadevan, S., Nalawade, S., Singh, J. B., Verma, A., Paul, B., \& Ramaswamy, K. (2010). EVOLUTION OF $\delta$ PHASE MICROSTRUCTURE IN ALLOY 718, 7-th International Symposium on Superalloy 718 and Derivatives, TMS (The Minerals, Metals \& Materials Society). https://doi.org/10.7449/2010/Superalloys_2010_737_750

\section{Contact information:}

Wojciech J. NOWAK, Dr.-Ing.

(Corresponding author)

Faculty of Mechanical Engineering and Aeronautics, Rzeszow University of Technology,

Powstanców Warszawy 8, 35-959 Rzeszów, Poland

E-mail:w.nowak@prz.edu.pl

Kamil OCHAL, M.Sc.

Faculty of Mechanical Engineering and Aeronautics, Rzeszow University of Technology,

Powstanców Warszawy 8, 35-959 Rzeszów, Poland

E-mail: kochal@prz.edu.pl

RyszardFILIP, Professor

Faculty of Mechanical Engineering and Aeronautics, Rzeszow University of Technology,

Powstanców Warszawy 8, 35-959 Rzeszów, Poland

E-mail: ryfil@prz.edu.pl

Bartek WIERZBA, Professor

Faculty of Mechanical Engineering and Aeronautics, Rzeszow University of Technology,

Powstanców Warszawy 8, 35-959 Rzeszów, Poland

E-mail: bwierzba@prz.edu.pl 